\title{
Covid-19 Policy Implications for Blended Learning in Higher Education in the Fourth Industrial Revolution
}

\author{
Johannes C Cronje \\ https://orcid.org/0000-0002-9838-4609 \\ Cape Peninsula University of Technology \\ johannes.cronje@gmail.com
}

\section{Abstract}

Universities have aspired to embrace the concepts of Schwab's Fourth Industrial Revolution with varying degrees of success. The Covid-19 epidemic, however, has created a disruption of unprecedented proportions. Managements of universities were forced to do whatever it took to save the academic year by means of emergency remote teaching. This form of teaching required a relaxation of numerous rules and policies that were designed primarily for contact institutions. Many of these concessions will probably be irrevocable and will require intensive revisions of university policies of teaching and learning. However, since teaching and learning do not exist in a vacuum, there are policy implications for all sections of the university. This autoethnographic desk study follows a theory-building approach by integrating the lived experience of the author with the current literature, to create a framework for the development and revision of policies to accommodate blended learning in higher education in the context of the Covid-19 pandemic and the Fourth Industrial Revolution (4IR). Although the definition and implementation of blended learning lie at the heart of issues regarding teaching and learning, policy adjustments will have to be made in all aspects of the university.

Keywords: Fourth Industrial Revolution (4IR); blended learning; Covid-19; learning policy; higher education

\section{Introduction}

The onset of the Covid-19 pandemic and its resultant lockdowns caused a very rapid transition from contact to emergency remote learning, and from there to blended learning. However, very few institutions had clear policies in place to deal with this change in the modus operandi of a university. This autoethnographic paper will develop a framework of aspects to consider when institutions develop or revise their various

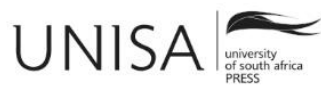




\section{Cronje}

policies to accommodate the changes brought about by the rapid pivot to blended learning because of the Covid-19 pandemic against the background of the challenges of the Fourth Industrial Revolution (hereafter 4IR).

The world-wide enthusiasm for Schwab's (2017) introduction of the term The Fourth Industrial Revolution has led to the widespread incorporation of the term in the vision and mission statements of universities world-wide. The implications of the 4IR in encouraging e-learning and open educational resources were obvious (Azhari et al. 2020; Mostert 2020). Nevertheless, institutions of higher learning were slow in adopting this new way of thinking (Oke and Fernandes 2020). Reasons for this slow adoption included outdated syllabi that were carried over from semester to semester, lack of engagement from tenured professors, lack of training of professors regarding contemporary educational technology and methods, and a focus on professor-centred, rather than student-centred learning (Sutton and Jorge 2020, 1).

In the first quarter of 2020, the outbreak of the Covid-19 novel coronavirus brought a significant portion of the academic world to a virtual standstill. Things changed almost overnight (Zhao 2020). Throughout the world, "online learning has become a new norm despite initial discomfort and disconnect" (Peters et al. 2020, 3). As a result "the speed of popularization of online education may exceed our imagination" (Peters et al. 2020, 6). The speed of transformation has radically changed much of what we thought about how higher education works (or should work). The lessons "learned from the pandemic of 2020 will force a generation of new laws, regulations, platforms and solutions for future cases, when the countries, government and population will be more prepared than today" (Basilaia and Kvavadze 2020, 1). In the words of Hejia Wang: "Things could never be as simple as they used to be" (Peters et al. 2020, 7).

From a grounded theory perspective (Tarozzi 2020), this paper presents an autoethnographic (Koning and Moore 2020) perspective of the author-a senior manager closely involved in the development and implementation of policy at a large tertiary institution. The question that drives the study is:

How does the rapid transfer to blended learning influence policy review and development in higher education institutions during and after the Covid-19 pandemic?

\section{Method}

In this paper, I take a grounded theory approach, as it emphasises the close link between theoretical and empirical research and operates in the area that combines theory and empirical reality (Tarozzi 2020, 10). I draw from grounded theory its ability to collect and analyse data at the same time (Tarozzi 2020, 10). 


\section{Cronje}

In this research, I used two methods. The first is a structured review of the literature on the adoption of the 4IR in higher education, the disruptive nature of the Covid-19 pandemic, and policy review and development.

The second method is an autoethnographic reflection (Koning and Moore 2020) on my own lived experience as a senior manager at a large university. Input comes from my participation in meetings with management and my own staff; discussions with fellow deans, in person, via email or WhatsApp; interactions with my own first-year and graduate students; and conversations with fellow academics during various virtual conferences and workshops aimed at getting us through the pandemic. I use no direct information from these sources, but reflect on lessons learnt during the pandemic. I consider how they guided my own decision making and intuitive feelings towards policy revision and development.

I present my findings here not as a definitive set of guidelines, but as a sketch in the hope that they would resonate with the experiences of others. The study should contribute to the unfolding stories of Covid-19 and how it affected policy changes in the promotion of blended, open and distance learning during its devastating disruption of academia as we knew it.

\section{The Revolution and the Pandemic}

This literature survey will discuss the initial reluctance of the sector to embrace the 4IR and then consider the disruptive nature brought about by the Covid-19 pandemic.

\section{Adoption of the Fourth Industrial Revolution (4IR)}

The concept of the 4IR was first coined by the German Government in 2011, but it was Schwab (2017) who popularised the term. The era is characterised by advances in robotics, artificial intelligence, nanotechnology, quantum computing, biotechnology, the internet of things (IoT), decentralised consensus, 5G wireless technologies, 3D printing and fully autonomous vehicles (Culot et al. 2020). Higher education embraced technological advances as fields of study, but was reluctant to adopt the tools and techniques of the 4IR in their teaching and learning, and in their general way of thinking. Although there were some changes, "the sector is still reluctant in preparing and adapting to the current technology transformation" (Oke and Fernandes 2020, 5). Elements contributing to the success of the 4IR in teaching and learning include: perceived improvement of performance, ease of use, normative changes, and facilitation of the current education situation. Technology can only change learning together with other social and economic factors (Oke and Fernandes 2020, 19). Elements contributing to technological advancement can be grouped into five clusters:

1) Economic, with changes in growth, employment, and the nature of work.

2) Business, with new consumer expectations, production methods, data processing and presentation, collaboration innovation and new operating models. 


\section{Cronje}

3) Changes in the patterns of national and local government relationships in terms of state, region and city, as well as the concept of national security.

4) Community clusters with increasing inequality and crowding.

5) Individual clusters with changes in identity, morality and ethics, as well as changes in patterns of connections between people and the management of private and public information. (Komara 2020, 20)

\section{The Disruptive Nature of the Covid-19 Pandemic}

The shift from traditional teaching and learning to emergency remote teaching occurred almost overnight as governments world-wide enforced population lockdowns. A Chinese student reporting on her learning experience during Covid-19 confinement comments: "I would say it pushes us to a new learning era. E-learning keeps people, students, and teachers on pace with their studies, works, and their research" (Peters et al. 2020, 11). The key changes that were immediately brought about are characterised by: 1) Shifting from face-to-face to online classes; 2) changes in assessment and evaluation; 3) uncertainties for international students; 4) travel restrictions; 5) challenges to mental health because of anxiety and isolation; and 6) strong demands being made on support services from universities (Sahu 2020). It was found that students with strongly developed self-regulated learning skills were more likely to succeed (Gonzalez et al. 2020,2). On the other side of the classroom, it was found that two aspects, "teachers' experience and workload were strongly associated with successful technology integration in the learning process of students" (Yeop et al. 2019, 778).

\section{Policy Review and Development}

In explaining the value of university policy, Komara $(2020,20)$ argues that "Every decision has its own consequences. The series of policies becomes a symbiosis of mutualism in the form of a derivative of each policy in the Campus community." Nevertheless, Villar, López, and Herrero (2020) argue that current blended learning policy development in higher education is bringing public institutions closer to private systems such as in-house training divisions, since "in a scenario of academic capitalism, the widespread promotion of virtual training policies and the growth of blended learning are giving rise to similarities between public and private systems, resignifying institutional structures and creating new formulas in approaches to training processes" (Villar et al. 2020, 45). It may well be this move towards "academic capitalism" that drove the rapid acceptance of previously unheard practices in emergency remote teaching. Institutions of higher learning realised that, in the same way as private businesses, they too had to fight for survival. Johnston, MacNeill, and Smyth (2019) point out that "In essence the neoliberal approach to higher education is as an industry 'producing' degrees to be 'purchased' by student customers with the intention of career benefit to the consumer and the economy as a whole" (Johnston et al. 2019, 8).

In their draft policy brief on the SADC-ODeL response to Covid-19, the Distance Education Association of Southern Africa proposes that in developing or revising policies, consideration should be given to pedagogy, interaction, the process of learning, 


\section{Cronje}

learning materials, structures, and systems (Makoe and Gatsha 2019). They propose a three-phased approach: short term (crisis period), medium term (recovery period), and long term (sustainability period). In this paper, all three of those periods will be considered, while the elements for consideration will be covered as they occur within the traditional university functions of teaching and learning, research, community engagement, and management.

This section will consider the policy issues at three levels: Macro (governmental), meso (institutional), and micro (departmental or even lecturer).

At the macro level, Johnston et al. (2019, 3) identify a number of "change forces" influencing higher education in the twenty-first century. These forces include:

1) Neoliberal policies to reposition higher education as a market of providers and consumers.

2) The expansion of the number of institutions and an increase in the numbers of students.

3) Overemphasis on the contribution made by universities to economic growth and competitiveness.

4) Introduction of external mechanisms to measure the quality of teaching, research, and the performance of staff.

5) Digital technology itself, primarily positioned as a practical means of enhancing learning and teaching.

6) Critical responses to negative changes. (Johnston et al. 2019, 3)

At the meso level, Salmon and Asgari (2019) identify three areas that should drive policy. Firstly, there is the enablement of students towards life-long, responsible, personal development that should lead to a growth in mindset and mastery. Secondly, they call for the embracement of multiple technologies including sensors, wearable fabrics, augmented reality, and so forth, to transform educational experiences, and finally for universities to "learn from the future as it emerges" by actively seeking solutions outside the traditional university experience.

At the micro level, Toquero (2020, 2-3) makes five suggestions for academic departments:

1) Integrate environment and health courses in the curriculum.

2) Strengthen environmental policies and hygiene practices.

3) Incorporate online mental health and medical services.

4) Migrate courses, align curriculum competencies, and scale up teachers' training for online learning instruction.

5) Strengthen research efforts, data monitoring, and evidence-based practices.

Finally, of course, the role of students cannot be underestimated as they "generate alternative visions of the nature and purpose of universities and redraw the boundaries 


\section{Cronje}

of participation to engage a much wider and more varied university population" (Johnston et al. 2019, 6).

Covid-19 has become the disruption that may redefine the concept of the university and of teaching and learning in higher education on all three levels.

\section{Discussion: Lessons Learnt during the Pandemic}

A major shift to blended learning will have implications not only on teaching and learning policies, but also on various other policies of a university. I therefore break the discussion up into the traditional roles of university, namely teaching and learning, research, and community engagement. Then I acknowledge that the management of the university, a going concern, also needs to be addressed.

\section{Teaching and Learning}

Discussions of blended learning should emphasise learning rather than technology. Many universities currently have separate teaching and learning, e-learning, and assessment policies. Universities should develop an integrated teaching-learning policy. Technology is no longer an add-on to the teaching and learning process, "Although many institutions are introducing computers to support teaching and learning, we observed that 4IR is beyond the use of computers and has the potential to disrupt the way we teach, learn, and engage" (Oke and Fernandes 2020, 19). The move beyond the use of computers is particularly visible in the growth of mobile learning, which is increasingly considered "an essential educational technology component in higher education. It makes it possible for students to learn, collaborate, and share ideas" (Naciri et al. 2020,2). Currently, separate assessment policies should also be integrated into the teaching and learning policy, because "we need to think of our assessments as an integrated part of the curriculum and not just something we do after or separately from other aspects of instruction" (Scott 2020, 57). The section below will be divided into curriculum design, facilitation of learning, and assessment.

\section{Curriculum Design}

From discussions with colleagues, it became clear that remote teaching has at its very root the need to care for and monitor every student. Never has there been so great a need for a student-centred approach. Although much lip service has been paid to this aspect in the past, it is now necessary to redevelop the curriculum to put the student in the centre. Perhaps more than ever, there is also a need to move away from pure content teaching towards keeping "the spirit of intellect and movement in balance, to achieve the goals of Education, namely cognitive learning and practical competence" (Komara 2020, 19). Lecturing staff demonstrated that they were quickly able to transform their teaching practices to suit the new context, thus demonstrating that "Innovation in this context is nothing more than shorthand for the harnessing of the knowledge economyfor both research and educational experience - and is a vital and long-term input that will stimulate success in the STEM and STEAM fields" (Salmon and Asgari 2019). 


\section{Cronje}

With learners confined to their homes, access to online learning has become independent of distance or status, as "online learning is accessible to them without discrimination. In the unfortunate lockdown circumstances caused by the Covid-19 pandemic, online learning and teaching are useful tools to boost international education" (Peters et al. 2020, 6). Not only is the international nature of education boosting students who returned to their home countries and can still continue to be taught, but also international guest lecturers can now be invited - who do not have to travel-and thus the internationalisation of curriculum materials is facilitated.

The learner-centred approach also has implications for the chunking of learning materials and students call for much smaller pieces of information at a time. Lecturers agreed that such chunks could be around 10 minutes, while students seemed to show a preference for two and a half minutes - as long as a typical song. All this resonates with other findings that "In order to ensure that students concentrate on online study, faculty should reasonably break down the content of the in-class teaching into different topics and adopt a modular teaching method. In other words, on the basis of ensuring a clear knowledge structure in the curriculum, faculty divide the teaching content into several small modules" (Bao 2020, 114).

Being student-centred means designing for the "human" side of students, since:

Compared with traditional in-class lectures, faculty have less control over online teaching, and students are more likely to "skip the class." Therefore, the progress of online teaching and its learning effectiveness largely depend on students' high-level active learning outside of class. To this end, faculty should use various methods to moderately modify students' homework and reading requirements to strengthen students' active learning outside of class. (Bao 2020, 114)

In this respect, lecturers have found that using online time to brief students to do offline tasks helps maintain their interest.

\section{Facilitation of Learning}

Salmon and Asgari (2019) suggest that "the way learners are educated is just as important as what they are learning about." The role of instructors in modelling the learning process is becoming increasingly important. In this regard, there is a need to move away from the "paper behind the glass" paradigm of online learning (Oke and Fernandes 2020, 19). Over and above this, the real challenge lies in allowing the persona or "voice" of the facilitator to come through via the technology. Often the body language, facial expressions, and even tone of voice do not translate when text or other modes are used. I have found that sometimes my "tongue-in-cheek" humour is missed by students when we work in text or audio-only modes.

The need for teaching assistants, student coaches, and student mentors comes up constantly. Students simply need more support. Much of this support is nurturing- 


\section{Cronje}

related rather than content related. Thanks to various blended learning platforms, students can re-listen to recorded classes, watch videos through open platforms or platforms paid for by the university, but a friendly face and a helping hand are scarce. It is necessary, however, for there to be full communication between teaching staff and teaching assistants so that there is harmony between the intention of the instructor and the needs of the student (Bao 2020).

\section{Assessment and Evaluation}

The biggest single challenge in teaching and learning in the context of the 4IR and the Covid-19 pandemic lies in the changing nature and purpose of assessment and evaluation (Gonzalez et al. 2020). Final sit-down examinations have had to be cancelled in many instances and replaced by other methods. One of the problems here is that students and lecturers have been preparing for a certain type of assessment, only to discover at the last minute that it would be replaced by another. As Sahu (2020) points out, although universities have been using technology to support the delivery of learning materials, using technology for assessment is often under-developed. Problems reported in the literature and experienced in my environment include: deciding on an appropriate alternative; dealing with partially completed assignments; monitoring of continuous assessment tasks; assessing practical and laboratory work that cannot be done online; accommodating students who do not have adequate internet connections or digital devices; discussing a time frame for assessment; and finally, preventing cheating.

On the other hand, Gonzalez et al. (2020) reported that a move to continuous evaluation with regular feedback and rewards in the form of marks, led to the increased motivation of students and consequently increased performance. Smaller, regularly monitored tasks also improved students' time management skills. Similarly, students' confinement forced them to concentrate on their studies, as they had nothing else to do, but also because they were concerned about not completing the academic year (Gonzalez et al. 2020, 22).

\section{Research}

The extreme uncertainty created by Covid-19 has provided rich opportunities for novel research perspectives in many fields (Peters et al. 2020). Three areas of research come to mind. Primary research on the prevention and management of Covid-19 infections, the continuation of the academic project at the time of Covid-19, and research on the conversion of lessons learnt in teaching and learning during Covid-19 into mainstream practice in the context of the 4IR.

Primary research on the prevention and management of Covid-19 is likely to divert funding from other research activities (Nicola et al. 2020), including the scholarship of teaching and learning. 


\section{Cronje}

\section{Community Engagement}

Community engagement is one of the key functions of a university; it is also a key element in the prevention and management of the disease (Liu et al. 2020). While universities have clear policies and practices in place for the process of community engagement, work-integrated and service learning, the presence of the virus has required additional precautionary measures. In my experience, the most important concern lies in the indemnification of the university against the potential spread of the virus. Students may become infected, or they themselves could infect the community. Current university indemnity forms may have to be revised accordingly. Moreover, screening processes need to be put in place to minimise the risk (Liu et al. 2020). Sometimes it is possible to move community engagement online, while in the case of work-integrated learning, some employers who have a work-from-home policy have accommodated interns accordingly and allowed them to work from home also. In other instances where the industries themselves have ground to a halt, some courses are able to develop simulated work-integrated learning, while in the contact service industry (such as hospitality), this has simply not been possible, and it has been necessary to revise the curriculum to move such work into the next year of study. Where such industry placement is scheduled for the final year, this may be a problem.

\section{Management}

With universities going almost completely digital during Covid-19, and with an envisaged high residual retention of the digital component, one could argue that both the concept of university and digital could be regarded as "problematic and contestable constructs, which are subject to definition and redefinition by powerful sociocultural forces and political and economic interests" (Johnston et al. 2019, 6). Management will, therefore, have to reconsider the vision, mission, strategy and focus of the whole university going forward. This section will consider several implications for operations as well as leadership.

\section{Operations}

Taking the lead from general government practices, many universities have established task forces to deal with the crisis. This task force could be an expansion of the existing business continuity plan structures, but would be expanded to "include members from different areas within the university such as academics, human resources, facility management, health units, student affairs, enrolment services, and other relevant members. The task force should frequently meet with various subcommittees formed for the outbreak and make informed decisions as the situation evolves" (Sahu 2020, online).

On the other hand, many of the regular university operations had to be suspended or reimagined. Some universities have cancelled graduation ceremonies and allowed all students to graduate in absentia, while others have moved their graduation ceremonies 


\section{Cronje}

completely online. General maintenance and even infrastructure development programmes may have been interrupted or compromised.

\section{Administration}

The first impact of Covid-19 on the office of the registrar involved a major redesign of the annual calendar. Term dates had to change, as well as assessment dates and even graduation dates. Furthermore, the regulations had to be amended to allow for alternative assessment types. Finally, this also impacted the university's time table. In the post-Covid-19 world, it is likely that there will be a much wider range of assessments, which may call for a permanent redesign of these regulations. With both staff and students having developed a potential appetite for blended open and distance learning, timetables and venues are likely to change. Students and staff have indicated a preference for asynchronous teaching and learning - students prefer working at night, when bandwidth is also cheaper. Some academic staff find it difficult to work during the daytime when they are home schooling their children.

On the quality assurance front, it is necessary to ensure that students still receive the kind of education that they would have received under previous circumstances. Nevertheless, it may well be necessary for some adjustments to be made in terms of expected graduate attributes. If the world after Covid-19 is to be different than before, then the graduates should also be.

\section{Human capital}

With the enforcement of working from home, as well as the increased flexibility in working hours, regulations should be revised to concentrate on output and impact rather than on hours worked. At the same time, with various dates being revised, it would also be necessary to look at current leave schedules.

The second area of work lies in human resource development-training. It is evident that neither academic nor administrative staff are adequately trained in remote pedagogy or technology. Training needs to be provided, while at the same time recognition should be given to those who train themselves and who reach out to colleagues and students.

In general, reward and incentive schemes may be required both to reward the front runners and to encourage reluctant staff to work in new ways. At the same time, there is likely to be much maverick behaviour as enthusiastic staff may well try any new means at their disposal, while others may take unnecessary chances.

An issue that has been simmering for quite a while, but is certainly coming to the fore now, is the issue of privacy and intellectual property. While some staff have no problem recording themselves doing live presentations for re-use later, some staff object to video recordings of themselves and prefer to turn the video off. Some staff believe that they should own their material and be compensated for producing it. The ownership of such 


\section{Cronje}

materials is already covered by most university policies, but in some cases refinement is necessary. Lecturers have taken to finding open learning materials, either on ODeL sites or on the Internet generally, and encouraged students to use these, without necessarily consulting or adhering to the related copyright statements of such materials. The same goes for staff producing their own materials and sharing this on YouTube, LinkedIn Learning, or other platforms without considering the intellectual property rights of their own institutions, should they publish such material on third-party platforms.

\section{Finance}

University finances are generally thinly spread and the additional costs of responding to Covid-19 will have to be reallocated from somewhere. Some of this can be done by taking from events that will not happen, such as contact graduation, international travel, and so forth, while others may be covered by government aid and private donations. Nevertheless, universities have to be mindful that they are likely to suffer from bad debt resulting from students being unable to pay for courses as a result of poor economic circumstances. There may also be a reduction in student numbers in the following year or two.

Where, for many years, e-learning has been touted by its evangelists as a cost saver, it is becoming increasingly clear that teaching online may be more work-not less-and that the maintenance of e-learning infrastructure may well be a cost driver rather than a cost saver.

\section{Infrastructure}

While digital infrastructure may be more costly than was anticipated, physical infrastructure may end up being both costly and redundant.

\section{Digital Infrastructure}

Although universities acquire technology in pursuit of innovation, indecision, budgetary constraints, policies and politics often act as barriers to its use (Salmon and Asgari 2019). Nevertheless, students are likely to prefer engagement with their mobile devices than with physical books (Muhideen et al. 2019, 38). On the other hand, the rapid increase in the use of the digital infrastructure may cause an overload of digital platforms and unplanned shutdowns that may further disrupt teaching and learning.

The increased use of the digital infrastructure also puts increased pressure on the digital helpdesk, while the proliferation of platforms such as Zoom, Skype, Google Meets, Microsoft Teams, and many more, may confuse both students and lecturers. In the crisis period (Makoe and Gatsha 2019) it may be a good idea to allow such proliferation, but as we move towards the sustainability period, some degree of standardisation will be required to enable efficient services from the digital support department. In the meantime, "In order to solve all kinds of unexpected issues timely, faculty need to 


\section{Cronje}

prepare Plan B or even Plan C before classes start and inform students in advance" (Bao 2020, 114).

\section{Physical Infrastructure}

As students gradually return to campus, physical distancing requirements and sanitation are placing a heavy burden on the physical infrastructure, while at the same time leaving much of it largely unused. Lecturers who can avoid contact teaching are asked to do so, thus leaving lecture theatres abandoned, while laboratories cannot be fully occupied and some departments have taken to having students work in 24-hour shifts to allow access to all, with interesting consequences for cleaning staff. In many instances, students who have not had access to their own technology before, have now acquired it to continue working. Once these students return to campus, they will no longer need the computer laboratories in which their institution has invested so heavily. With portable computers in the possession of every student, there will be no need to teach in the laboratory next door. The regular classroom now doubles up as the laboratory and suddenly excess space will be available. As is usual in educational spaces, hard walls will once again be one of the biggest constraints to development. There will be a distinct move of students out of classrooms and laboratories to less formal working spaces. Furthermore, the architecture of classrooms with one wall dedicated to the "Smart board" will become redundant as each student's small screen will, of necessity, be a smart board. Moreover, an increase in the demand for off-site asynchronous learning will mean less pressure on physical spaces, and - in a perverse reversal of matters - a pedagogy will have to be developed that will encourage students to come to class when they have learnt to learn at home.

\section{Student Services}

With the current anxiety about completing the "academic year" we are forgetting that learning subject material is but one component of university life. "The Campus arena is a living environment full of intellectual dynamics and movement, the place and period of psychological, intellectual, and social transition" (Komara 2020, 18). With students away from this space, it is difficult to develop this social transition, although one sees that transition taking place in the proliferation of social media groups that students start for themselves, which begs the question: "How do students, connected virtually but separated physically in an internationalized university, deal with disruption brought about by the Covid-19 pandemic" (Peters et al. 2020,3)?

Currently, university student services are concentrating on the stress students experience as a result of the emergency, which is to be expected from the first crisis phase described by Makoe and Gatsha (2019). However, as we enter the sustainability phase, the deans of students of higher education institutions will have to consider very seriously what the digital student life experience should look like. 


\section{Cronje}

\section{Marketing and Communication}

The marketing and communication function is both inward and outward looking. On the one hand, they must ensure that they recruit the best possible future students and the most willing donors, while on the other hand, they should ensure an appropriate flow of accurate information to students and staff.

Emergency communication is not the sole responsibility of the marketing and communication function. Two of the key problems leading to internal chaos during the pandemic arise from platform and time. The proliferation of communication platforms means that messages may be missed or hard to retrieve. Management and students alike have created a plethora of WhatsApp groups to communicate quickly, but in their anxiety, people easily spread disinformation, or cause unnecessary conflict through debate. During the crisis phase, there was a tendency for information to flow through whatever channel was handiest at a given stage - this could be orally during online meetings (in which people forget to take and circulate minutes); informally over WhatsApp; or formally via email. The problem here is that conflicting information can be spread through these channels, and the information can be difficult to retrieve. To make matters worse, many email clients default to "Reply to all" so that one's mailbox is often clogged with 30 messages that say "noted."

The panic of the emergency also created the suspension of normal working hours. Emails might be sent by a senior manager at the close of business, which will then be sent on by the next in line to their next in line in succession and people would find themselves working late into the night on work that could have been done the next morning - just to "get it off their desks." This lack of discipline (of sticking to working hours) creates an even higher state of anxiety, fatigue, and frustration.

These two problems should be addressed in the recovery period described by Makoe and Gatsha (2019), as they will delay the sustainability period from coming into effect. Going into a post-Covid-19 world with the proliferation of technologies of the 4IR, it is essential that better communication protocols and infrastructures should be developed through the improved use of collaborative tools such as SharePoint or other similar products, most of which have already been purchased by institutions, but not used effectively.

\section{Leadership}

The pandemic requires leadership across all disciplines. We need to recognise that "science, education, and human experience are completely inseparable in our postdigital era, and that our international Covid-19 effort requires interdisciplinary collaboration across them all"(Peters et al. 2020, 19).

In order to accommodate this diversity in a time of crisis, there is a need for considerable flexibility. As university leaders try to create stability by producing new rules that are 


\section{Cronje}

essentially digital versions of the old ones, they create high levels of anxiety as staff worry about being able to adjust to such rigid circumstances. Instead, stability should be created by developing resilience through flexibility and anti-fragility. We have to realise that none of us has done this before. All of us will make mistakes. All of us have the right to be forgiven. None of us has the right not to try.

\section{Conclusions and Recommendations}

The question that drove this study was:

How does the rapid transfer to blended learning influence policy review and development for higher education institutions during and after the Covid-19 pandemic?

From the literature and from my own lived experience, it has become clear that every section of the university is affected by the introduction of blended learning, and that often an intervention in one aspect has ramifications in another. The introduction of digital technology requires more training, but could also render some physical spaces obsolete or require them to be re-used. Much of the existing policy may already cover many aspects, but may well have to be tweaked, while other policy items may have to be rewritten altogether to facilitate growth towards a new sustainable post-Covid-19 higher education system that is more closely aligned with the demands and opportunities of the 4IR.

\section{References}

Azhari, B., A. Ma'awiyah, M. Hamid, M. Ridhwan, and S. Bahri. 2020. "E-Learning as Connector among Education Institution in the 4th Industrial Revolution." JPhCS 1471 (1): 12024. https://doi.org/10.1088/1742-6596/1471/1/012024.

Bao, W. 2020. "Covid-19 and Online Teaching in Higher Education: A Case Study of Peking University." Human Behavior and Emerging Technologies 2 (2): 113-115. https://doi.org/10.1002/hbe2.191.

Basilaia, G., and D. Kvavadze. 2020. "Transition to Online Education in Schools during a SARS-CoV-2 Coronavirus (Covid-19) Pandemic in Georgia." Pedagogical Research 5 (4). https://doi.org/10.29333/pr/7937.

Culot, G., G. Nassimbeni, G. Orzes, and M. Sartor. 2020. "Behind the Definition of Industry 4.0: Analysis and Open Questions." International Journal of Production Economics, no. 226: 107617. https://doi.org/https://doi.org/10.1016/j.ijpe.2020.107617.

Gonzalez, T., M. A. de la Rubia, K. P. Hincz, M. Comas-Lopez, L. Subirats, S. Fort, and G. M. Sacha. 2020. Influence of Covid-19 Confinement in Students' Performance in Higher Education, 1-25. https://doi.org/10.1371/journal.pone.0239490; https://doi.org/10.35542/osf.io/9zuac. 


\section{Cronje}

Johnston, B., S. MacNeill, and K. Smyth. 2019. Conceptualising the Digital University: The Intersection of Policy, Pedagogy and Practice. Springer. https://doi.org/10.1007/978-3319-99160-3.

Komara, E. 2020. The Challenges of Higher Education Institutions in Facing the Industrial Revolution 4. 0. 3 (May), 15-26.

Koning, J., and L. Moore. 2020. “Autoethnography.” In Doing Coaching Research, 91-111, edited by P. Jackson, and E. Cox. SAGE Publications.

Liu, Y., Z. Wang, Y. Tian, M. Zhou, T. Zhou, K. Ye, Y. Zhao, Y. Qiu, J. Li, and J. Ren. 2020. "Design and Development of Covid-19 Risk Assessment Decision Support System for General Practitioners." Journal of Medical Internet Research. https://doi.org/10.2196/preprints.19786.

Makoe, M., and G. Gatsha. 2019. Policy Brief SADC-ODeL Response to Covid-19. Distance Education Association of Southern Africa.

https://www.deasa.org/deasa/announcements/Policy\%20brief\%20DEASA\%20response $\% 2$ 0Covid\%200420\%20(1).pdf.

Mostert, C. 2020. "Embarking on the Open Education Resources Journey in the 4th Industrial Revolution.” In EdMedia + Innovate Learning, 950-959.

Muhideen, S., Y. Yen, S. Iddrisu, M. Amin, and W. Bertha. 2019. "The Adoption of an MLearning Policy in Higher Education: The Professionals' Perspective in Developing Countries." Humanities and Social Sciences Letters 7 (1): 29-45.

Naciri, A., M. A. Baba, A. Achbani, and A. Kharbach. 2020. "Mobile Learning in Higher Education: Unavoidable Alternative during Covid-19." Aquademia [online] 4 (1). https://doi.org/10.29333/aquademia/8227.

Nicola, M., Z. Alsafi, C. Sohrabi, A. Kerwan, and A. Al-jabir. 2020. The Socio-economic Implications of the Coronavirus Pandemic (Covid-19): A Review. January. https://doi.org/10.1016/j.ijsu.2020.04.018.

Oke, A., and F. A. P. Fernandes. 2020. "Innovations in Teaching and Learning: Exploring the Perceptions of the Education Sector on the 4th Industrial Revolution (4IR)." Journal of Open Innovation: Technology, Market, and Complexity 6 (2). https://doi.org/10.3390/JOITMC6020031.

Peters, M. A., H. Wang, M. O. Ogunniran, Y. Huang, B. Green, J. O. Chunga, E. A. Quainoo, Z. Ren, S. Hollings, C. Mou, S. W. Khomera, M. Zhang, S. Zhou, A. Laimeche, W. Zheng, R. Xu, L. Jackson, and S. Hayes. 2020. “China's Internationalized Higher Education During Covid-19: Collective Student Autoethnography." In Postdigital Science and Education, 1-21. https://doi.org/10.1007/s42438-020-00128-1. 


\section{Cronje}

Sahu, P. 2020. "Closure of Universities due to Coronavirus Disease 2019 (Covid-19): Impact on Education and Mental Health of Students and Academic Staff." Cureus, no. 12 (4). https://doi.org/10.7759/cureus.7541.

Salmon, G., and T. Asgari. 2019. "Higher Education-the Last Bastion? Distance and eLearning Policy and Development: The Role of e-Learning and Distance Education in the Modernisation Process of Economies, Societies and Education Systems." European Journal of Open, Distance and E-Learning, no. 22 (1).

Schwab, K. 2017. The Fourth Industrial Revolution. Currency.

Scott, I. M. 2020. "Beyond 'Driving': The Relationship between Assessment, Performance and Learning.” Medical Education 54 (1): 54-59. https://doi.org/10.1111/medu.13935.

Sutton, M. J. D., and C. F. B. Jorge. 2020. "Potential for Radical Change in Higher Education Learning Spaces after the Pandemic." Journal of Applied Learning and Teaching 3 (1): 15. https://doi.org/10.37074/jalt.2020.3.1.20.

Tarozzi, M. 2020. What is Grounded Theory? Bloomsbury Publishing. https://doi.org/10.5040/9781350085275/

Toquero, C. M. 2020. “Challenges and Opportunities for Higher Education amid the Covid-19 Pandemic: The Philippine Context.” Pedagogical Research 5 (4): em0063. https://doi.org/10.29333/pr/7947.

Villar, L. B. E., G. Á. López, and M. L. L Herrero. 2020. “The Policy Approach of B-learning. The University Model of Education in the Public-Private Binomial." In Blended Learning: Convergence between Technology and Pedagogy, 45-63. Springer. https://doi.org/10.1007/978-3-030-45781-5_3.

Yeop, M. A., M. F. M. Yaakob, K. T. Wong, Y. Don, and F. M. Zain. 2019. “Implementation of ICT Policy (Blended Learning Approach): Investigating Factors of Behavioural Intention and Use Behaviour.” International Journal of Instruction 12 (1): 767-782. https://doi.org/10.29333/iji.2019.12149a.

Zhao, Y. 2020. “Covid-19 as a Catalyst for Educational Change.” Prospects, 1-5. https://doi.org/10.1007/s11125-020-09477-y. 